\title{
Artificial produced water as a medium to grow Chlorella sp. for biodiesel production
}

\author{
Deby Hajjar Rakhmadumila ${ }^{1, *}$, and Barti Setiani Muntalif ${ }^{1}$ \\ ${ }^{1}$ Environmental Engineering Department, Institut Teknologi Bandung, Indonesia
}

\begin{abstract}
Increased interest in renewable, carbon-neutral energy sources makes processing biodiesel from microalgae has become the objective for many researchers and companies. Some kind of wastewater including municipal, industrial and agricultural wastewaters have been identified as alternate growth mediums. Produced water is the largest byproduct of the oil and natural gas extraction process which constitutes of high concentration of pollutants, such as dissolved nitrogen, phosphorus, dissolved organic carbon, heavy metal and monocyclic aromatic compound like BTEX. The purpose of this study is to identify Chlorella sp. potential for producing lipid in artificial produced water. Variations made in this study consist of $0 \%, 25 \%, 50 \%, 75 \%$ and $100 \%$ volume of artificial produced water to the control Walne medium. The highest specific growth rate and biomass productivity of Chlorella $\mathrm{sp}$. achieved by culture grown in $25 \%$ wastewater with a value of $0.225 \mathrm{day}^{-1}$ and $0.175 \mathrm{~g} \mathrm{~L}^{-1} \mathrm{day}^{1}$, respectively. The highest lipid yield and productivity in mixed culture of artificial produced water and Walne medium achieved by culture in $25 \%$ artificial produced water with value of 0.231 and $40.48 \mathrm{mg} \cdot \mathrm{L}^{-1}$.day ${ }^{-1}$. C16 and C18 fatty acids which dominated the lipids of Chlorella sp. in all culture variations indicated that the lipid of Chlorella sp. were suitable for producing high quality biodiesel.
\end{abstract}

\section{Introduction}

Over-consumption of petroleum based-energy has led to environmental problem such as global climate change and energy crisis. Due to that, there is a great demand for alternative resources of petroleum-based energy. Biofuels, produced from biomass, are promising alternatives to fossil-derived fuels due to several distinct advantages including carbon neutrality, reduced emissions of gaseous pollutants (e.g., carbon monoxide, $\mathrm{CO}_{2}$, and sulfur oxides), continuous availability of biomass feed stocks, and their safety of production by farming [1]. One type of biofuels, biodiesel is a mixture of fatty acid methyl esters (FAME) which is conventionally produced by transesterification of vegetable oils or animal fats [2]. Microalgae have been recognized as promising oil feedstock for biodiesel production due to their rapid growth rate, high lipid content and their ability to grow in non-arable area without competing with food crops for land. Microalgae convert solar energy into chemical energy via $\mathrm{CO}_{2}$ fixation.

However, biodiesel production from microalgae is expensive due to large amount of water and inorganic nutrients (nitrogen, phosphate, and $\mathrm{CO}_{2}$ ) needed. In order to reduce production cost, many researcher has used wastewater as alternative nutrient source to grow microalgae and the wastewater also can be bioremediated prior to discharge. By this means, microalgae provides mutual benefit of producing biofuels while removing nitrogen, phosphorus, and organic carbon from wastewater [3]. Wastewater that had been used as nutrient sources for growing microalgae were agricultural waste, domestic waste and industrial waste.

Oil and gas industry produces a significant amount of industrial wastewater which trapped in underground formations that is brought to the surface along with oil or gas. This water has been in contact with hydrocarbonbearing formation for centuries, it contains some of the chemical characteristics of the formation and the hydrocarbon itself. It may include water from the formation, water injected into the formation, and any chemicals added during the production and treatment processes. These varied sources of water reach the production well, and is known as produced water (PW) [4]. In general, PW contains a various concentration of hydrocarbons, phenols, BTEX (benzene, toluene, ethylbenzene, and xylene), heavy metals and many inorganic salts [5]. These complex constituents exhibit toxicity to environment and the toxicity increased with the increasing amount of produced water generation. Recent studies used microalgae to remove produced water pollutants and produce biomass $[6,7,8]$. Chlorella

\footnotetext{
"Corresponding author: debyrakhmadumila18@gmail,com
} 
sp. removed $58.89 \%, 73.38 \%, 30.75 \%$ of total nitrogen, total phosphorus and total organic carbon respectively [6]. Chlorella sp. also obtained dry biomass up to 0.2 $\mathrm{g} / \mathrm{L}$ in $100 \%$ PW [6]. In other studies, Nannochloropsis oculata was able to remove carbon as chemical oxygen demand (COD) up to $54 \%$ and produced biomass up to $0.311 \mathrm{~g} / \mathrm{L}$ in $50 \%$ PW loading [7]

Due to the presence of organic constituent in produced water, cultivating microalgae in $\mathrm{PW}$ is mixotrophic cultivation. Organic carbon and light energy are simultaneously supplied to algae in this type of cultivation. This strategy of fixing $\mathrm{CO}_{2}$ and assimilating organic carbon supplied concomitantly promises to greatly increase the cell concentration and lipid content of microalgae [9]. Green microalgae, Chlorella which commonly applied for human food, animal feed and bioactive compounds, recently reported as the potential biodiesel feedstock due to their high lipid productivity and environmental adaptation. Mixotrophic grown Chlorella sorokiniana had a total lipid content of $34.7 \%$, higher than the photoautotrophically grown cells $(9 \%)$ and heterotrophically grown cells $(17.6 \%)$ in 8 $\mathrm{g} / \mathrm{L}$ initial glucose [9]. In other studies, Chlorella vulgaris obtained total lipid content of $25.4 \%$ in $1 / 800$ monosodium glutamate wastewater (MSGW) concentration, higher than photoautotrophically grown cells $(22.65 \%)$ [3]. The FAME composition of Chlorella vulgaris grown in domestic wastewater consisted of C16:1 (Methyl Palmitoleate) C17:0 (Methyl Heptadecanoate), C18:0 (Methyl Stearate), C18:1 (Methyl Oleate) and C18:2 (Methyl Linoleate). These fatty acids are usually found in other oil bearing crops such as soybean, sunflower and palm oil. which have been confirmed to be suitable for biodiesel production [10].

There have been many works on producing biodiesel from mixotrophically grown Chlorella sp. and few works on cultivating microalgae in PW, but there is still no report investigates biodiesel production in $\mathrm{PW}$ grown microalgae. More details on total lipid content and distribution of fatty acids in PW grown microalgae are still required. To meet this call, this study explored the feasibility of growing Chlorella sp. in artificial produced water and its potential as biodiesel feedstock.

\section{Methodology}

The studies were conducted with the marine microalgae Chlorella sp. from the culture collection of Biochemistry Laboratory of Chemistry Department, Institut Teknologi Bandung. Five cultivation experiment were carried out to evaluate the growth conditions, lipid content and fatty acid content of Chlorella sp. in five different concentrations of artificial produced water (from 0 to $100 \%$ ). Cell densities, dry biomass weight, organic content and lipid content of microalgae were analyzed every day. At the end of cultivation, Chlorella sp. was collected to be dried and extracted for its lipid. The lipid then was transesterified to obtain fatty acid methyl esters (FAMEs) or biodiesel. Analysis of the fatty acids was done to determine the potential of Chlorella sp. as a biodiesel feedstock.

\subsection{Making growth media and artificial produced water}

Nutrients media used for growth of Chlorella sp. was Walne media. The artificial produced water used in this study refered to the characteristics of produced water from an Indonesian oil field, located in Balikpapan [11]. The chemicals used to make artificial produced wastewater were crude oil, $\mathrm{NH}_{4} \mathrm{Cl}$, phenol, $\mathrm{KNO}_{3}$, $\mathrm{KH}_{2} \mathrm{PO} 4$ and $\mathrm{Na}_{2} \mathrm{~S}$. Artificial produced water used for cultivation was prior filtered to remove suspended solids and dispersed oils which could block the entry of light into the culture. Walne medium and artificial produced water were also sterilized by autoclaves to eliminate contaminants from other microorganisms that could disrupt growth. Table 1 shows the characteristics of artificial produced wastewater.

Table 1. Characteristics of artificial produced water

\begin{tabular}{|c|c|c|c|}
\hline No & Parameter & Unit & $\begin{array}{c}\text { Artificial } \\
\text { produced } \\
\text { water }\end{array}$ \\
\hline 1 & $\mathrm{pH}$ & - & 8.19 \\
\hline 2 & Temperature & ${ }^{\circ} \mathrm{C}$ & 24.7 \\
\hline 3 & COD & $\mathrm{mg} / \mathrm{L}$ & 4100 \\
\hline 4 & Oil and grease & $\mathrm{mg} / \mathrm{L}$ & 48.08 \\
\hline 5 & Nitrate & $\mathrm{mg} / \mathrm{L}$ & 2.544 \\
\hline 6 & Nitrite & $\mathrm{mg} / \mathrm{L}$ & 0.26 \\
\hline 7 & Total Nitrogen & $\mathrm{mg} / \mathrm{L}$ & 29.74 \\
\hline 8 & Total Phosphate & $\mathrm{mg} / \mathrm{L}$ & 0.22 \\
\hline 9 & Ortophosphate & $\mathrm{mg} / \mathrm{L}$ & 0.057 \\
\hline 10 & TDS & $\mathrm{mg} / \mathrm{L}$ & 10730 \\
\hline 11 & Ammonia & $\mathrm{mg} / \mathrm{L}$ & 26.572 \\
\hline 12 & Phenol Total & $\mathrm{mg} / \mathrm{L}$ & 323.42 \\
\hline 13 & Total Sulfide & $\mathrm{mg} / \mathrm{L}$ & 0.778 \\
\hline
\end{tabular}

\subsection{Cultivation procedure}

\subsubsection{Preliminary cultivation}

As a preliminary cultivation and in order to attain a sufficient initial inoculums cell density. Chlorella sp. was cultured by adding $10 \mathrm{~mL}$ inoculate in $1 \mathrm{~L}$ glass flask containing $810 \mathrm{~mL}$ of Walne nutrient media, aerated with ambient air with surrounding temperature ranging from 25 to $28{ }^{\circ} \mathrm{C}$ and illuminated with 4000 lux light intensity under $12: 12 \mathrm{~h}$ light/dark cycle. This inoculation was lasted until four days or until Chlorella sp. reaching the exponential phase. The contents of Walne were as follows: $\mathrm{FeCl}_{3} 0.87 \mathrm{mg} / \mathrm{L}, \mathrm{MnCl}_{2} .4 \mathrm{H}_{2} \mathrm{O}$ $0.36 \mathrm{mg} / \mathrm{L}, \quad \mathrm{Na}_{2} \mathrm{EDTA} 54.24 \mathrm{mg} / \mathrm{L}, \quad \mathrm{NaH}_{2} \mathrm{PO}_{4} .2 \mathrm{H}_{2} \mathrm{O}$ $17.66 \mathrm{mg} / \mathrm{L}, \mathrm{NaNO}_{3} 100.264 \mathrm{mg} / \mathrm{L}, \mathrm{ZnCl}_{2} 0.021 \mathrm{mg} / \mathrm{L}$, $\mathrm{CoCl}_{2} \cdot 6 \mathrm{H}_{2} \mathrm{O} \quad 0.011 \mathrm{mg} / \mathrm{L}, \quad\left(\mathrm{NH}_{4}\right)_{6} \mathrm{Mo}_{7} \mathrm{O}_{24} \cdot 4 \mathrm{H}_{2} \mathrm{O} \quad 0.009$ $\mathrm{mg} / \mathrm{L}, \mathrm{CuSO}_{4} .5 \mathrm{H}_{2} \mathrm{O} 0.02 \mathrm{mg} / \mathrm{L}$, Vitamin $\mathrm{B} 1$ (Thiamine $\mathrm{HCl}) 10 \times 10^{-5} \mathrm{mg} / \mathrm{L}$ and Vitamin B12 (Cyanocobalamin) $5 \times 10^{-6} \mathrm{mg} / \mathrm{L}$. 


\subsubsection{Cultivation in artificial PW}

Chlorella sp. was grown in five different concentrations of artificial PW media (from 0 to $100 \%$ ) using $8 \mathrm{~L}$ working volume. Microalgae grown in $0 \%$ artificial produced water (Variation 0\%) used as control in this study. Microalgae that had grown in preliminary cultivation was re-inoculated in each artificial PW media concentration. Table 2 demonstrates the cultivation experiment in $\mathrm{PW}$ media.

Table 2. Five variations of cultivation performed in $8 \mathrm{~L}$ total working volume

\begin{tabular}{|c|c|c|c|c|}
\hline Variation & $\begin{array}{c}\text { Volume of } \\
\text { Walne } \\
\text { medium } \\
(\mathbf{\% )}\end{array}$ & $\begin{array}{c}\text { Volume of } \\
\text { artificial } \\
\text { PW (\%) }\end{array}$ & $\begin{array}{c}\text { Volume } \\
\text { of Walne } \\
\text { medium } \\
\text { (L) }\end{array}$ & $\begin{array}{c}\text { Volume of } \\
\text { artificial } \\
\text { PW (L) }\end{array}$ \\
\hline $0 \%$ & 100 & 0 & 8 & 0 \\
\hline $25 \%$ & 75 & 25 & 6 & 2 \\
\hline $50 \%$ & 50 & 50 & 4 & 4 \\
\hline $75 \%$ & 25 & 75 & 2 & 6 \\
\hline $100 \%$ & 0 & 100 & 0 & 8 \\
\hline
\end{tabular}

All cultivation experiments were carried out in a cylindrical plastic container with $10 \mathrm{~L}$ capacity placed within closed incubator with dimensions of length $x$ width $\times$ height of $(1.5 \times 0.6 \times 0.6) \mathrm{m}^{3}$, made from plywood and coated with aluminum foil. Microalgae cultivation was carried out in batch system at 25 to $28{ }^{\circ} \mathrm{C}$ and 4000 lux light intensity under 12:12 h light/dark cycle. Continuous filtered air with constant flow was introduced into the reactor using aquarium air pumps with 1 LPM output flow. All the batch experiments were carried out in duplicate

Cultivation was carried out in 13 days. Sterile pipette was used for sampling microalgae culture to prevent contamination from other microorganisms.

\subsection{Determination of Chlorella sp. growth}

Microalgae growth was measured everyday by cells count in a Neubauer Hematocytometer using light microscope with 40× final magnification [1] and biomass concentration as dry weight $(\mathrm{g} / \mathrm{L})$ and organic content $(\mathrm{g} / \mathrm{L})$.

Dry weight of microalgae was determined by separation from the media using centrifugation. $200 \mathrm{~mL}$ cell suspension was centrifuged at $4000 \mathrm{rpm}$ for 30 minutes and then dried at $105{ }^{\circ} \mathrm{C}$ for an hour and subsequently cooled to room temperature in a desiccator before weighting [1]. Organic content of microalgae was determined by putting dry biomass obtained prior into furnace at $600{ }^{\circ} \mathrm{C}$ for an hour and subsequently cooled to room temperature in a desiccator before weighting. Standard deviations of the average values are presented on diagrams.

The specific growth rate $(\mu)$ at the exponential phase was calculated by

$$
\mu=\frac{\left(\ln X_{2}-\ln X_{1}\right)}{t_{2}-t_{1}}
$$

where $\mathrm{X}_{2}$ and $\mathrm{X}_{1}$ were cell density/ dry biomass/ organic content of microalgae $(\mathrm{g} / \mathrm{L})$ at time of $t_{2}$ and $t_{1}$, respectively. The relationship between specific growth rate and carbon concentration as substrate was fitted to a Monod growth kinetic model using the equation:

$$
\mu=\mu_{\max } \frac{S}{K_{\mu}+S}
$$

where $\mu$ was the specific growth rate $\left(\right.$ day $\left.^{-1}\right)$ calculated during the linear portion of exponential phase growth (Equation 1), $\mu_{\mathrm{m}}$ was the maximum specific growth rate $\left(\right.$ day $\left.^{-1}\right)$, S was the $\mathrm{C}$ concentration $(\mathrm{mg} / \mathrm{L} \mathrm{C})$, and $\mathrm{K}_{\mu}$ (half saturation constant $\mathrm{mg} / \mathrm{L} \quad \mathrm{C}$ ) was the $\mathrm{C}$ concentration at $\mu_{\mathrm{m}} / 2$ [12]. The cells yield was determined by subtracting the highest cell abundance $\left(\mathrm{X}_{\max }\right)$ form the minium value $\left(\mathrm{X}_{0}\right)[8]$.

$$
X=X_{\max }-X_{0}
$$

Biomass productivity (P) was determined by using equation:

$$
P=\frac{\left(X_{2}-X_{1}\right)}{t_{2}-t_{1}}
$$

\subsection{Lipid extraction}

The total lipid content of Chlorella sp. was analyzed gravimetrically everyday by the soxhlet extraction method. The solvent used in this extraction was nhexane. An aliquot $(200 \mathrm{~mL})$ of the sample was collected and the algal pellets were then dried using an oven (105 ${ }^{\circ} \mathrm{C}, 1$ hour). The dried algal pellets were extracted with $150 \mathrm{~mL}$ of $\mathrm{n}$-hexane for 4 hours of heating. After the extraction process finished, the results lipids were distilled to separate the lipids and n-hexane solvent. After that, the lipid was weighed. Lipid yield $(\mathrm{Y})$ and productivity $\left(\mathrm{L}_{\mathrm{p}}\right)$ was calculated by

$$
\begin{gathered}
Y=\frac{\left(L_{f}-L_{0}\right)}{\left(X_{f}-X_{0}\right)} \\
L_{P}=\frac{X_{f} \times L C}{V o l \times \Delta t}
\end{gathered}
$$

where $\mathrm{L}_{\mathrm{f}}$ and $\mathrm{L}_{0}$ were the final and initial lipid concentration $(g / L) . X_{f}$ and $X_{0}$ were the final and initial biomass concentration $(\mathrm{g} / \mathrm{L})$. LC was lipid content (\%). Vol was working volume and $\Delta \mathrm{t}$ was cultivation time (13 days).

\subsection{Preparation of FAME}

The lipid sample $(100 \mathrm{mg})$ was added to an erlenmeyer followed by $\mathrm{NaOCH}_{3}(2 \mathrm{~mL})$. The erlenmeyer was the covered with aluminium foil paper and then placed at the shaker with a speed of $150 \mathrm{rpm}$, at $60^{\circ} \mathrm{C}$ for \pm 24 hours. After cooling to room temperature, $9.5 \mathrm{~mL}$ methanol and $238 \mu \mathrm{L} 98 \% \mathrm{H}_{2} \mathrm{SO}_{4}$ were added. The reaction continued in a shaker again with a speed of $150 \mathrm{rpm}$, at $60^{\circ} \mathrm{C}$ for 1 hour. After cooling to room temperature, the mixture 
was transferred to a centrifuge tube $(50 \mathrm{~mL})$ followed by $19 \mathrm{~mL} \mathrm{NaCl}(5 \% \mathrm{w} / \mathrm{v})$ and $11.9 \mathrm{~mL} \mathrm{n}$-hexane. The esters formed were extracted in hexane. The tubes were vortexed and centrifuged (4500 rpm for 10 minutes), resulting in two immiscible phases. The upper phase which was the hexane layer with FAMEs was dried over anhydrous sodium sulphate. The FAMEs was recovered into a vial and subjected to gas chromatography-mass spectrometry (GC-MS) analysis.

\subsection{Fatty acid methyl esters analysis}

The fatty acid composition of biodiesel was performed in a Shimadzu QP2010 Ultra gas chromatograph (GC). The GC condition were as follows: coloumn DB-5, a column temperature program that specified an injector temperature of $280{ }^{\circ} \mathrm{C}$, an oven temperature program of $60-280{ }^{\circ} \mathrm{C}\left(4{ }^{\circ} \mathrm{C} / \mathrm{min}\right)$, use of $\mathrm{N}_{2}$ as a carrier gas and velocity in the coloumn was controlled at $41,7 \mathrm{~cm} / \mathrm{s}$.

\section{Result and discussions}

\subsection{Microalgae growth}

The growth of Chlorella sp. in different concentrations of produced water was indicated by cell densities, dry weight, organic content and total lipid content.

\subsubsection{Cell density of Chlorella sp.}

To Examine the possibility of utilization of the mixture of artificial produced water (PW) and Walne medium to cultivate Chlorella sp., the algal cells were cultured in five different concentrations of artificial produced water. Artificial produced water made in this study had high concentration of organic carbon (see. Methodology) due to the presence of high concentration phenol and oil and grease. The result of growth experiments are shown in Fig.1. Growth result indicated an increased cell density for Chlorella sp. in all different concentration of artificial PW. The initial cell abundance used in all cultivation was $0.5 \times 10^{6}$ cell $/ \mathrm{mL}$. Initial growth period for Chlorella sp. had an unnoticeable difference lag phase within all different artificial PW concentrations. The lag phase was three days in all variations.

Maximum day growth and maximum cell numbers of Chlorella sp. are shown in Table 3. The highest microalgae cell density was reached on $10-11^{\text {th }}$ day of cultivation in all variations, except for the one grown in $100 \%$ artificial PW. Nannochloropsis oculata reached highest cell density on the $9^{\text {th }}$ day in pure PW, while in $0 \% \mathrm{PW}$ highest cell density was reached on $12^{\text {th }}$ day [8]. Therefore, the dilution of produced water had an effect on the growth of microalgae. The highest cell yield of Chlorella $\mathrm{sp}$. was achieved in $75 \%$ artificial PW and the smallest cell yield was achieved in $50 \%$ artificial PW (Table 3).

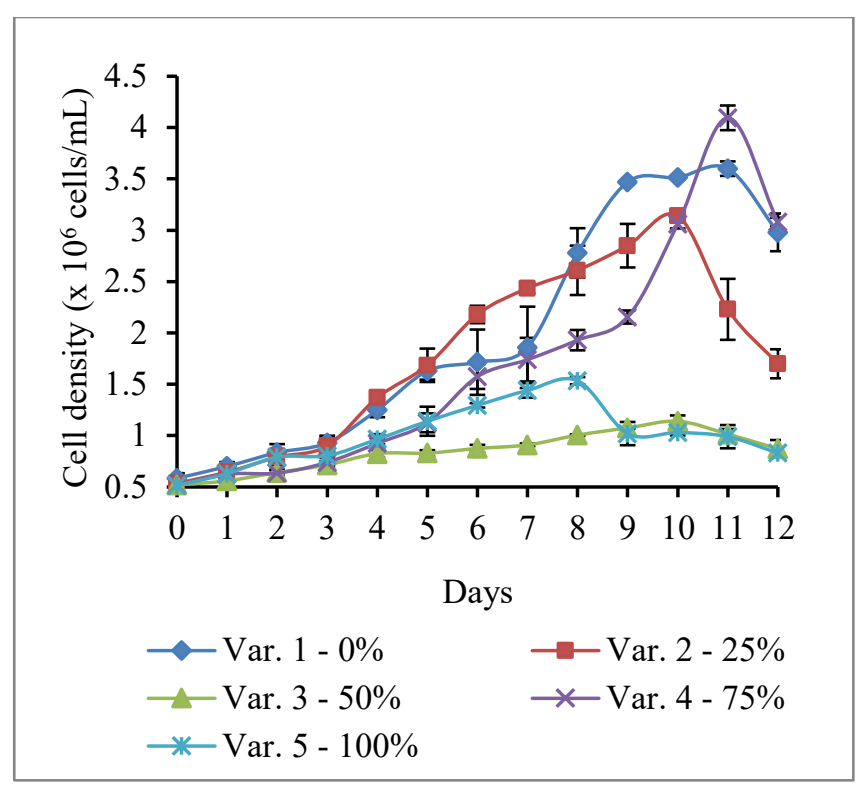

Figure 1. Growth curves of Chlorella sp. in artificial produced water with different concentrations

Table 3. Growth parameters of Chlorella sp. in five different concentrations

\begin{tabular}{|c|c|c|c|}
\hline Variation & $\begin{array}{c}\text { Max. day } \\
\text { growth } \\
(\mathbf{d})\end{array}$ & $\begin{array}{c}\text { Max. cell number } \\
\left(\times 10^{6} \text { cells } / \mathbf{m L}\right)\end{array}$ & $\begin{array}{c}\text { Cell yield } \\
\left(\times 10^{6} \text { cells/mL }\right)\end{array}$ \\
\hline $\begin{array}{c}0 \% \\
(\text { control })\end{array}$ & 11 & $3.6 \pm 0.07$ & $3.02 \pm 0.021$ \\
\hline $25 \%$ & 10 & $3.14 \pm 0.057$ & $2.61 \pm 0.035$ \\
\hline $50 \%$ & 10 & $1.14 \pm 0.057$ & $0.62 \pm 0.071$ \\
\hline $75 \%$ & 11 & $4.09 \pm 0.12$ & $3.58 \pm 0.134$ \\
\hline $100 \%$ & 8 & $1.53 \pm 0.035$ & $1.02 \pm 0.028$ \\
\hline
\end{tabular}

It is very likely that the physiological stress caused by the compounds present in artificial produced water generated the lower results achieved in these experiments [8]. The cell yield of Chlorella sp. in 100\% artificial PW was also smaller than that achieved by Nannochloropsis oculata $\left(2.71 \times 10^{6}\right.$ cells $\left./ \mathrm{mL}\right)$ which was also grown in $100 \%$ produced water [8].

The specific growth rate at artificial PW loadings of $0 \%, 25 \%, 50 \%, 75 \%$ and $100 \%$ are shown in Table 4 . Comparing the five different concentrations of artificial PW media, the specific growth rates of microalgae tends to be decreased with the increasing of artificial PW concentrations. The specific growth rate of Chlorella sp. in $100 \%$ artificial produced water was higher than that in Nannochloropsis oculata which achieved 0.09 day $^{-1}$ using $100 \%$ produced water [8].

Table 4. Specific growth rate $(\mu)$ and cell yield of Chlorella sp. in five different concentrations

\begin{tabular}{|c|c|}
\hline Variation & $\boldsymbol{\mu}\left(\mathbf{d a y}^{-1}\right)$ \\
\hline $0 \%$ (control) & $0.192 \pm 0.021$ \\
\hline $25 \%$ & $0.189 \pm 0.001$ \\
\hline $50 \%$ & $0.076 \pm 0.001$ \\
\hline $75 \%$ & $0.183 \pm 0.004$ \\
\hline $100 \%$ & $0.136 \pm 0.005$ \\
\hline
\end{tabular}


Calculation of maximum growth rate $\left(\mu_{\max }\right)$ and substrate constant (Ks) that achieved by microalgae Chlorella sp. was done with carbon substrate because carbon plays an important role in microalgae growth. Based on the calculation, it was obtained that $\mu_{\max }$ was 0.1205 and Ks was 122.8. This showed that if Chlorella sp. was grown in cultures with carbon below 122,8 $\mathrm{mg} / \mathrm{L}$, the maximum growth rate will not be achieved.

\subsubsection{Dry biomass of Chlorella sp.}

Dry biomass and organic content were results of microalgae cell growth by assimilating nutrients in medium into their cells. Based on experiments, the results of microalgae dry biomass and organic content were shown in Figure 2 and Figure 3 below.

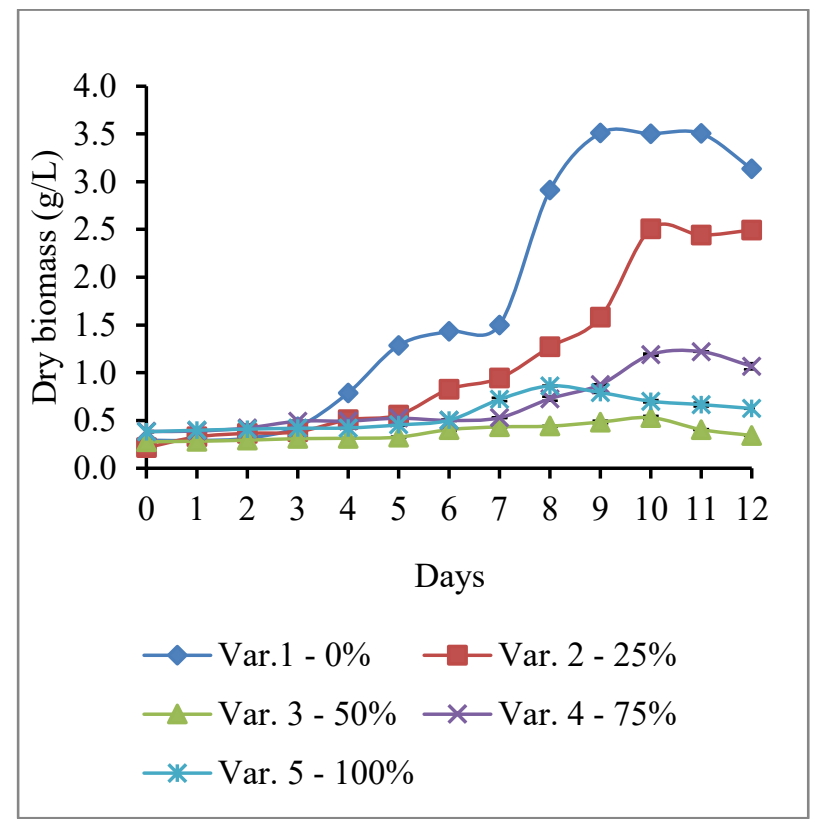

Figure 2. Dry biomass of Chlorella sp.

The growth of Chlorella sp. in control (Walne media) obtained the highest biomass concentration where after three days of lag period biomass growth up to $3.509 \mathrm{~g} / \mathrm{L}$. While Chlorella sp. grown in $25 \%$ and $50 \%$ artificial PW had five days of lag period. Chlorella sp. grown in $75 \%$ and $100 \%$ artificial PW had six days of lag period (Fig. 2). A different result was observed in Chlorella sp. which was grown in $100 \%$ produced water. had only 2 day of lag period [6]. This difference was probably due to different concentration of compounds present in produced water.

Table 5 shows maximum dry biomass concentration and biomass productivity achieved by Chlorella sp. in all five different concentrations of artificial PW. Highest biomass concentration was achieved by Chlorella $\mathrm{sp}$. in $25 \%$ artificial $\mathrm{PW}$. The biomass concentration dropped from $2.506 \mathrm{~g} / \mathrm{L}$ to $0.86 \mathrm{~g} / \mathrm{L}$ when the artificial PW concentration increased from $25 \%$ to $100 \%$ suggesting an inhibition of microalgal growth in high artificial PW concentration. Contaminates such as metals, nutrients and other organic compounds present in PW may justifies the lower biomass production in treatments where PW was increased.

Table 5. Growth parameters of Chlorella sp. in five different concentrations

\begin{tabular}{|c|c|c|}
\hline Variation & $\begin{array}{c}\text { Max. dry } \\
\text { biomass (g/L) }\end{array}$ & $\begin{array}{c}\text { Biomass } \\
\text { productivity } \\
\text { (g/L/day) }\end{array}$ \\
\hline $\begin{array}{c}0 \% \\
\text { control) }\end{array}$ & $3.509 \pm 0.002$ & $0.219 \pm 0.001$ \\
\hline $25 \%$ & $2.506 \pm 0.002$ & $0.175 \pm 0.007$ \\
\hline $50 \%$ & $0.53 \pm 0.018$ & $0.005 \pm 0.0002$ \\
\hline $75 \%$ & $1.22 \pm 0.002$ & $0.052 \pm 0.002$ \\
\hline $100 \%$ & $0.86 \pm 0.003$ & $0.019 \pm 0.0004$ \\
\hline
\end{tabular}

However, the maximum dry weight achieved by Chlorella sp. in 50\% artificial PW was higher than those achieved by Nannochloropsis oculata $(0.31 \mathrm{~g} / \mathrm{L})$ and Isochrysis galbana $(0.314 \mathrm{~g} / \mathrm{L})$ in $50 \%$ produced water [7]. The maximum dry weight achieved by Chlorella sp. in $100 \%$ artificial PW was also higher than that achieved by Chlorella sp. (0.2 g/L) grown in $100 \% \mathrm{PW}$ [6]

The highest biomass productivity achieved by Chlorella sp. in 25\% artificial PW (Table 5). The biomass productivity decreases with increasing artificial PW suggesting an inhibition of microalgal growth in high artificial PW concentrations. Biomass productivity achived by Chlorella vulgaris in mixotrophic cultivation suppplied by bold basal media (0.180) was higher than highest biomass productivity of Chlorella sp. in this study. This may be attributed by some compounds in this artificial wastewater. But the biomass productivity of Chlorella sp. in $25 \%$ artificial PW was still higher than other cultivations of Chlorella grown in wastewater media. Chlorella vulgaris achieved biomass productivity of $0.0409 \mathrm{~g} / \mathrm{L} /$ day and $0.0615 \mathrm{~g} / \mathrm{L} /$ day in $0.02 \mathrm{v} / \mathrm{v}$ domestic water and 100- fold diluted MSG (monosodium glutamate wastewater), respectively $[3,10]$. Based on that, artificial PW seems becoming a better alternative wastewater medium to grow Chlorella.

Table 6. Specific growth rate of Chlorella sp. in artificial produced water

\begin{tabular}{|c|c|}
\hline Variation & $\boldsymbol{\mu}\left(\right.$ day $\left.^{-1}\right)$ \\
\hline $0 \%$ (control) & $0.304 \pm 0.0007$ \\
\hline $25 \%$ & $0.225 \pm 0.019$ \\
\hline $50 \%$ & $0.068 \pm 0.001$ \\
\hline $75 \%$ & $0.104 \pm 0.001$ \\
\hline $100 \%$ & $0.092 \pm 0.001$ \\
\hline
\end{tabular}

The cultivation of Chlorella sp. in the medium containing 25\% artificial PW also recorded the highest specific growth rate $\left(0.225\right.$ day $\left.^{-1}\right)$ (Table 6). This value was not as different compared with Chlorella vulgaris grown in $0.02 \mathrm{v} / \mathrm{v}$ domestic wastewater $\left(0.3 \mathrm{day}^{-1}\right)$ and in bold basal medium $\left(0.29\right.$ day $\left.^{-1}\right)[10,13]$. 


\subsubsection{Lipid content of Chlorella sp.}

Chemical solvent is the most reliable method in lipid extraction to determine total microalgae lipid content due to the high polarity of fatty acids [14]. In the present study, hexane was used as chemical solvent in extracting lipid of microalgae. Total lipid content of algal biomass for each variation was shown in Figure 3.

Based on measurements, the highest lipid content was achieved by the culture with $25 \%$ artificial PW $(0.5695 \mathrm{~g} / \mathrm{L})$ on the $11^{\text {th }}$ day. While the lowest lipid content was achieved by culture with $50 \%$ artificial PW, with value of $0.0638 \mathrm{~g} / \mathrm{L}$.

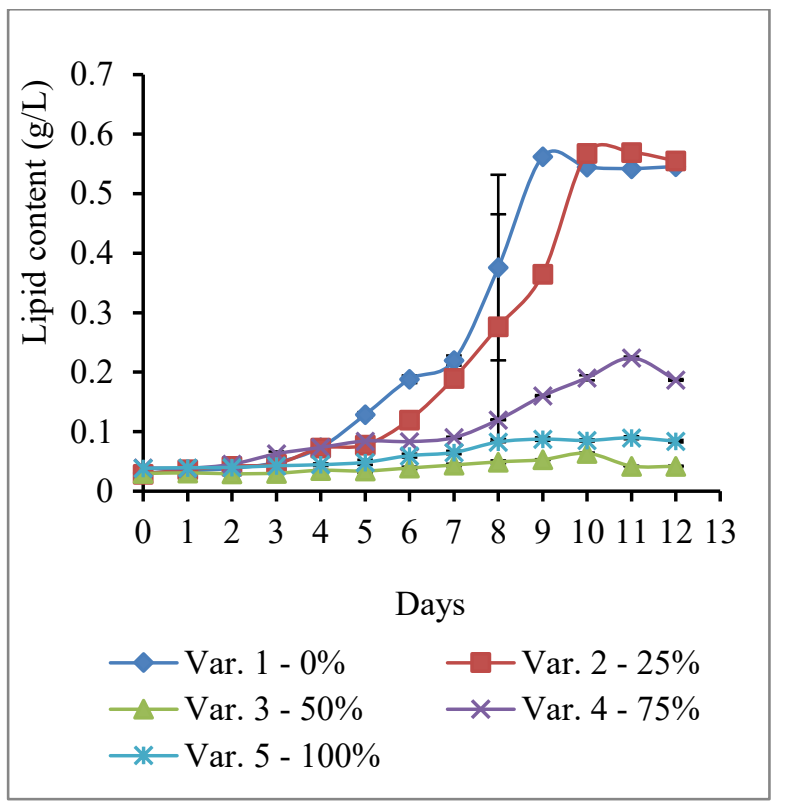

Figure 3. Lipid content of Chlorella sp.

The total lipid percentage of algal biomass in this study were between $12.04 \%$ and $23.33 \%$ under different artificial PW concentrations. These values were similar with Chlorella vulgaris (between $13.5 \%$ and $25.4 \%$ ) which was cultivated under different MSGW concentrations [3]. Lipid percentage from the five culture variations was obtained by dividing the highest weight of lipids produced with the weight of dry biomass on that day. The highest lipid percentage was achieved by culture with $25 \%$ artificial PW, with value of $23.33 \%$, then followed by $75 \%$ artificial $\mathrm{PW}$, with value of $18.35 \%$ and the smallest lipid percentage was achieved by culture with $50 \%$ artificial PW with value of $12.04 \%$. Whereas, lipid percentage of Chlorella sp. in 100\% artificial PW was $13.47 \%$. Lipid percentage of Chlorella sp. in $25 \%$ artificial PW which containing $80.86 \mathrm{mg} / \mathrm{L}$ phenol was close to that achieved by Dunaliella salina (21\%) which was also cultivated in $100 \mathrm{mg} / \mathrm{L}$ phenol [15]. The highest lipid content of Chlorella sp. which was achieved in $25 \%$ artificial PW was also higher than those achieved by C.pyrenoidosa which was cultivated in glycerol $(17.3 \%)$ and acetate $(13.4 \%)$.

Lipid yield was calculated to determine lipid productivity in each gram of dry biomass (gram lipid / gram biomass). Yield lipid and lipid productivity of Chlorella sp. in each variation shown in Table 7.
Table 7. Yield and lipid productivity of Chlorella sp.

\begin{tabular}{|c|c|c|}
\hline Variation & Yield Lipid & $\begin{array}{c}\text { Productivity } \\
\text { (mg/L.day) }\end{array}$ \\
\hline $0 \%$ (control) & $0.181 \pm 0.0003$ & 39.596 \\
\hline $25 \%$ & $0.231 \pm 0.01$ & 40.481 \\
\hline $50 \%$ & $0.18 \pm 0.006$ & 2.614 \\
\hline $75 \%$ & $0.217 \pm 0.013$ & 11.385 \\
\hline $100 \%$ & $0.186 \pm 0.004$ & 3.5 \\
\hline
\end{tabular}

Lipid productivity of Chlorella sp. in artificial PW was in the range between 2.614 and $40.481 \mathrm{mg} / \mathrm{L} /$ day. The largest lipid yield and lipid productivity were achieved by culture in $25 \%$ artificial PW. Comparing those five values of lipid productivity, the lipid productivity tends to be decreased with the decreasing of phosphate in cultures. The more concentration of artificial water, the less phosphate in media. This was consistent with lipid productivity achieved in Chlorella zofingiensis. Lipid productivity of C. zofingiensis when the amount of nitrogen and phosphate was sufficient in media, was $68.1 \mathrm{mg} / \mathrm{L}$. day. However, when cultivated in cultures with phosphate deficiency, the productivity was reduced to $44.7 \mathrm{mg}$ / L. days [16].

Highest lipid productivity achieved by Chlorella sp. in $25 \%$ artificial PW $(40.481 \mathrm{mg} / \mathrm{L} /$ day $)$ was higher than the highest lipid productivity achieved by Chlorella vulgaris $(12.50 \mathrm{mg} / \mathrm{L} /$ day $)$ which was cultivated in $1 / 100$ monosodium glutamate wastewater [3]

\subsection{Identification of Lipid Chlorella sp.}

Fatty acid methyl ester (FAME) is the main component of biodiesel and therefore, the chemical composition of distinctive FAME profile plays a critical role in determining the properties of biodiesel produced [10]. A transesterification / alcoholysis process was carried out to convert triacylglycerol to FAME.

Identification of the types of lipids produced by microalgae Chlorella sp. performed by GC-MS (Gas Chromatography - Mass Spectometry) using fatty acid standards. Lipids analyzed were lipids produced from microalgae Chlorella sp. in all variations of culture. FAME composition of Chlorella sp. in those five different concentration of artificial PW was shown in Table 8.

Table 8. Fatty acids methyl esters of artificial produced water grown Chlorella sp. by GC-MS

\begin{tabular}{|c|c|c|c|c|c|}
\hline \multirow{2}{*}{ Fatty acid } & \multicolumn{5}{|c|}{ FAME composition (\%) } \\
\cline { 2 - 6 } & $0 \%$ & $25 \%$ & $50 \%$ & $75 \%$ & $100 \%$ \\
\hline $\mathrm{C} 14: 0$ & 0.9 & 0.6 & - & - & - \\
\hline $\mathrm{C} 16: 0$ & 17.78 & 15.59 & 22.94 & 23.01 & 75.65 \\
\hline $\mathrm{C} 16: 1$ & 4 & 7.91 & - & 6.08 & - \\
\hline $\mathrm{C} 16: 2$ & 11.8 & - & - & - & - \\
\hline $\mathrm{C} 18: 0$ & 2.66 & 1.75 & - & 5.59 & - \\
\hline $\mathrm{C} 18: 1$ & - & 17.19 & - & 50.5 & - \\
\hline $\mathrm{C} 18: 2$ & 17.48 & 44.68 & 54.55 & 13.85 & 12.24 \\
\hline $\mathrm{C} 18: 3$ & 7.57 & - & - & - & - \\
\hline $\mathrm{C} 20: 0$ & 2.4 & - & - & - & - \\
\hline
\end{tabular}




\begin{tabular}{|c|c|c|c|c|c|}
\hline \multirow{2}{*}{ Fatty acid } & \multicolumn{5}{|c|}{ FAME composition (\%) } \\
\cline { 2 - 6 } & $0 \%$ & $25 \%$ & $50 \%$ & $75 \%$ & $100 \%$ \\
\hline TFA & 64.59 & 87.72 & 77.49 & 99.03 & 87.89 \\
\hline SFA & 23.74 & 17.94 & 22.94 & 28.6 & 75.65 \\
\hline MUFA & 4 & 25.1 & - & 56.58 & - \\
\hline PUFA & 36.85 & 44.68 & 54.55 & 13.85 & 12.24 \\
\hline
\end{tabular}

Note: $S F A=$ Saturated Fatty Acid, MUFA= Monounsaturated Fatty Acid, PUFA = Polyunsaturated Fatty Acid

The overall FAME composition of Chlorella sp. was mostly consisted of palmitic acid (C16:0) and linoleic acid (C18:2). The amount of C16:0 in Chlorella sp. ranged between $15.59 \%$ and $75.65 \%$. The amount of C16:0 was increased with increasing amount of artificial PW and it was the dominant fatty acid in the culture with $0 \%$ and $100 \%$ artificial PW. Whereas, the amount of C18:2 in Chlorella sp. ranged between $12.24 \%$ and $54.55 \%$. Palmitoleate acid (C16:1) and stearic acid (C18:0) were also found in almost all culture variations. Myristic acid (C14:0) was only found in cultures with $0 \%$ and $25 \%$ artificial $\mathrm{PW}$ with value of $0.9 \%$ and $0.6 \%$, respectively. Arachidic acid (C20:0) was only found in $0 \%$ artificial $\mathrm{PW}$ with value of $2.4 \%$. Myristic acid (C14:0) and arachidic acid (C20:0) was found in small amounts, compared to other $\mathrm{C} 16$ and $\mathrm{C} 18$ fatty acids. The abundance of $\mathrm{C} 16$ and $\mathrm{C} 18$ fatty acids in $0 \%, 25 \%$, $50 \%, 75 \%$ and $100 \%$ artificial PW were $61.29 \%$, $87.12 \%, 77.49 \%, 99.03 \%$ and $87.89 \%$, respectively. Palmitoleate acid (16:1) was found in the culture with $0 \%, 25 \%$ and $75 \%$ artificial PW. Stearic acid was found in culture with $0 \%, 25 \%$ and $75 \%$ artificial $\mathrm{PW}$. Hexadecadienoic acid (C16:2) and linolenic acid (C18:3) were only found in the lipids of Chlorella sp. grown in $0 \%$ artificial $\mathrm{PW}$. Oleic acid (C18:1) was present in culture of $25 \%$ and $75 \%$ artificial PW.

Based on Table 8 it can be seen that palmitic acid (C16:0) and linoleic acid (C18:2) are the dominant fatty acids found in the culture of Chlorella sp. in all variations. Bagul et al., 2017 states that microalgae oil which contains high levels of palmitic acid and linoleic acid can meet European standards on biodiesel [17]. The quality requirements of biodiesel in Indonesia itself are regulated by SNI 7182: 2015 with the test parameters of density at $40^{\circ} \mathrm{C}$, kinematic viscosity at $40^{\circ} \mathrm{C}$, cetane numbers, flash points, fog points, copper plate corrosion, carbon residues, water and sediment, $90 \%$ distillation temperature sulfuric ash, phosphorus, acid number, free glycerol, total glycerol, methyl ester content, iodine number, monoglyceride level and oxidation stability. From the nineteen parameters, parameters that can be assessed qualitatively based on the percentage of methyl esters were kinematic viscosity (KV), cetane number $(\mathrm{CN})$, oxidative stability and methyl ester content. One parameter that is also important to determine the characteristics of biodiesel is the high heating value (HHV).

Based on kinematic viscosity (KV), cetane number $(\mathrm{CN})$, oxidative stability, methyl ester content and high heating value (HHV), each culture variation was given a value of 1 to 5. A value of 1 indicates the composition of the FAME in culture was able to give the best results in those biodiesel parameters, while a value of 5 indicates the composition of FAME in culture could caused the worst results in those parameters. The value of the five parameters was determined by the composition of FAME contained in the lipids of Chlorella sp., so that a qualitative assessment can be made. Therefore, the percentage of saturated fatty acids (SFA), monounsaturated fatty acids (MUFA) and polyunsaturated fatty acids (PUFA) was calculated in each culture (Table 8).

The cetane number $(\mathrm{CN})$ is a dimensionless number showing the combustion quality of a diesel engine and is a leading indicator of biodiesel quality. The value of cetane numbers greatly influences engine performance parameters such as combustion and exhaust emissions and the higher value of cetane numbers is also associated with lower nitrogen oxide exhaust emissions. The branching and length of the molecular chains affect the value of cetane numbers, with their value decreased by decreasing the length of the chain and increasing branches in the molecular chain. Unbranched and long chain fatty acids produced good conventional biodiesel oil, which represents fast fuel combustion. A low cetane number indicates a long ignition delay which is a delay in fuel injection and the start of combustion. Higher CNs promote faster automatic ignition of fuel, and often lead to lower NOx emissions. So that the assessment of cetane numbers on biodiesel Chlorella sp. based on the percentage of $\mathrm{C} 18$ and $\mathrm{C} 16$ fatty acids in culture, because all fatty acids observed in the culture of Chlorella sp. in all variations had no branches, both the saturated and unsaturated fatty acids. The culture with the highest percentage of $\mathrm{C} 18$ and $\mathrm{C} 16$ fatty acids received a value of 1 in weighting, while the culture with the percentage of $\mathrm{C} 18$ and $\mathrm{C} 16$ fatty acids had the least value of 5 (Table 9).

Table 9. Weighting calculation for biodiesels in each culture variation

\begin{tabular}{|c|c|c|c|c|c|}
\hline \multirow{2}{*}{ Parameter } & \multicolumn{5}{|c|}{$\begin{array}{c}\text { Weighting value of biodiesel in each } \\
\text { culture variation }\end{array}$} \\
\cline { 2 - 6 } & $\mathbf{0 \%}$ & $\mathbf{2 5 \%}$ & $\mathbf{5 0 \%}$ & $\mathbf{7 5 \%}$ & $\mathbf{1 0 0 \%}$ \\
\hline $\begin{array}{c}\text { Cetane } \\
\text { number }\end{array}$ & 5 & 3 & 4 & 1 & 2 \\
\hline $\begin{array}{c}\text { Kinematic } \\
\text { Viscocity }\end{array}$ & 5 & 3 & 4 & 1 & 2 \\
\hline $\begin{array}{c}\text { Oxidative } \\
\text { stability }\end{array}$ & 4 & 3 & 5 & 2 & 1 \\
\hline $\begin{array}{c}\text { High } \\
\text { Heating } \\
\text { Value }\end{array}$ & 2 & 5 & 3 & 4 & 1 \\
\hline $\begin{array}{c}\text { Methyl esters } \\
\text { percentage }\end{array}$ & 5 & 3 & 4 & 1 & 2 \\
\hline Total & 21 & 17 & 20 & 9 & 8 \\
\hline
\end{tabular}

High viscosity of biodiesel can cause operational problems, such as the formation of deposits on the engine. In addition, higher density and viscosity values caused poor atomization and poor mixing of fuel and air 
which causes poor combustion and ultimately reduces engine efficiency. The viscosity value of a biodiesel is known to increased with increasing fatty acid chain length. So the weighting values for all cultures in this kinematic viscosity parameter are same as those in the cetane number parameter (Table 9).

The oxidative stability index is measured within a few hours and is related to the amount and position of unsaturation of fatty acids, which when damaged caused biodiesel oxidation. Oxidative stability decreased with increasing content of polyunsaturated fatty acids. So the weighting value of 1 is given to the culture with the smallest amount of polyunsaturated fatty acids (PUFA) (Table 9).

HHV is a unit of measurement of energy that is produced when a fuel has complete combustion. When HHV increased, fuel consumption will decrease [18]. HHV increased with increasing fatty acid chain length and decreased with increasing unsaturation of fatty acids. So the weighting value of 1 is given to the culture with the smallest amount of polyunsaturated fatty acids (Table 9).

Based on the weighting value, it can be seen that the Chlorella sp. in culture of $100 \% \mathrm{PW}$ get the smallest weighting value, which means the composition of FAME contained in the culture of $100 \%$ artificial PW were capable in producing biodiesel with the best characteristics. Based on Table 9, it can also be concluded that the characteristics of biodiesel obtained by Chlorella sp. starting from the best were culture with $100 \%, 75 \%, 25 \%, 50 \%$ and $0 \%$ artificial. This shows the lipid of Chlorella sp. cultivated in $100 \%$ artificial produced water and in those mixtures of Walne medium and artificial produced water are able to produce biodiesel with better quality than that grown in Walne medium only.

\section{Conclusions}

Based on the results of the study, microalgae Chlorella sp. was able to grow in the mixture of Walne medium and artificial produced water. The highest specific growth rate and biomass productivity of Chlorella sp. achieved by culture grown in $25 \%$ wastewater with a value of $0.225 \mathrm{day}^{-1}$ and $0.175 \mathrm{~g} \mathrm{~L}^{-1} \mathrm{day}^{-1}$, respectively. The highest lipid yield and productivity in culture of mixed produced water and Walne medium achieved by culture in $25 \%$ produced water with value of 0.231 and $40.48 \mathrm{mg} \cdot \mathrm{L}^{-1} \cdot$ day $^{-1}$. C16 and C18 fatty acids which dominated the lipids of Chlorella sp. in all culture variations indicated that the lipid of Chlorella sp. were suitable for producing high quality biodiesel. Based on qualitative calculations, biodiesel produced by Chlorella sp. in $100 \%$ produced water has the best biodiesel quality, based on parameters of cetane number, kinematic viscosity, oxidative stability, methyl ester content and high heating value.

\section{References}

1. Y. Li, S. Lian, D. Tong, R. Song, W. Yang, Y. Fan, R. Qing, C. Hu, Appl. Energy, 88, 3313-3317(2011)

2. S. Zhu, Y. Wang, C. Shang, Z. Wang, J. Xu, Z. Yuan, J. Biosci. Bioeng., 120, 205-209 (2015)

3. Y. Ji, W. Hu, X. Li, G. Ma, M. Song, H. Pei, Bioresour. Technol. 152, 471-476 (2014)

4. J. A. Veil, Produced Water: Environmental Risks and Advances in Mitigation Technologies, 537-571(2011)

5. J. C. Campos, R. M. H. Borges, A. M. O. Filho, R. Nobrega, G. L. S. Anna, Water Res. 36, 95-104 (2002)

6. M. A. A. Hakim, M. A. Al-Ghouti, P. Das, M. AbuDieyeh, T. A. Ahmed, H. M. S. J. Aljabri, Desalin. Water. Treat. 135, 47-58 (2018)

7. S. H. Ammar, H. J. Khadim, A. I. Mohamed, Environ. Technol. Innov. 10, 132-142 (2018)

8. A. A. Arriada, P. C. Abreu, Braz. J. Pet. Gas. 8, 119 125 (2014)

9. T. Li, Y. Zheng, L. Yu, S. Chen, Biomass Bioenergy. 66, 1-10 (2014)

10. M. K. Lam, M. I. Yusoff, Y. Uemura, J. W. Lim, C. G. Khoo, K. T. Lee, H. C. Ong, Renew. Energy. 103, 197-207 (2017)

11. E. Kardena, S. Hidayat, S. Nora, Q. Helmy, J Pet. Environ. Biotechnol. 8, 1-6 (2017)

12. Z. Hu, S. Duan, N. Xu, M. R. Mulholland, PLoS One. 9, 1-11 (2014)

13. P. Rattanapoltee, P. Kaewkannetra, Energy. 78, 1-5 (2014).

14. M. K. Lam, K. T. Lee, Appl. Energy. 94, 303-308 (2012)

15. K. Cho, C. Lee, K. Ko, Y. J. Lee, K. N. Kim, M. K. Kim, Y. H. Chung, D. Kim, I. K. Yeo, T. Oda, Algal Res. 17, 61-66 (2016)

16. P. Feng, Z. Deng, L. Fan, Z. Hu, J. Biosci. Bioeng. 114, 405-410 (2012)

17. S. Y. Bagul, R. Bharti, W. D. Dhar, Water Sci. Technol. 184, 230-235 (2017)

18. G. Knothe, Energ. Fuel. 22, 1358-1364 (2008) 